\title{
¡Urgente, urgente! Re-naturalicemos la escuela en tiempos de pandemia
}

\author{
Ester García-González \\ Departamento de Dicáctica, Área de Didáctica de las Ciencias Experimentales, Facultad \\ de Educación, Universidad de Cádiz. esther.garcia@uca.es \\ ORCID: https://orcid.org/0000-0003-0995-9798
}

[Recibido: 10 Junio 2020. Revisado: 11 Junio 2020. Aceptado: 11 Junio 2020]

\begin{abstract}
Resumen: Este escrito nace en tiempos de crisis, entendiendo esta como una oportunidad para emprender nuevos caminos. Es fruto de la reflexión en torno a la importancia del contacto de los seres humanos con la naturaleza. Es una llamada a reconectar con nuestro entorno en la que se propone a la escuela como un agente clave. En él se reflexiona sobre la necesidad de pasar tiempo de la jornada escolar al aire libre como una vía necesaria para esta reconexión. Se propone incluir a la naturaleza en el centro de los procesos de enseñanza-aprendizaje y, por tanto, se plantean cambios en las formas de organizar la escuela y las prácticas educativas. Se trata solo de poner sobre el papel algunos pensamientos e ideas que creemos pueden ser inspiradoras para abordar los desafíos presentes y futuros.
\end{abstract}

Palabras clave: Educación al aire libre, Escuela, Naturaleza, Crisis

\section{Warning! Let's re-naturalize school in pandemic times}

\begin{abstract}
This work is born in crisis times, understood as an opportunity to explore new avenues. It is a reflection about the relevance of the relationship between nature and human beings, it is a call for the reconnection with our environment, hence the schools should play a key role. It reflects on the requirement of spending time outdoors during the school day like a straight way towards the reconnection. Nature should be considered as the center of learning-teaching processes, it implies changes in the school organization and the educational practices. This contribution aims to highlight some thoughts and ideas that we think can be inspiring to afford the present and future challenges.
\end{abstract}

Keywords: Outdoor education, School, Nature, Crisis

Para citar este artículo: García-González, E. (2020) ¡Urgente, urgente! Re-naturalicemos la escuela en tiempos de pandemia. Revista de Educación Ambiental y Sostenibilidad 2(1), 1501. doi: 10.25267/Rev_educ_ambient_sostenibilidad.2020.v2.11.1501

\section{La crisis sanitaria, un aviso para despertar}

Estos últimos meses nos están haciendo reflexionar sobre lo frágiles que somos los seres humanos. No se trata esta de una idea nueva, pero claramente la crisis sanitaria provocada por el COVID-19 está haciendo más evidente nuestra pequeñez y fragilidad. Un virus, algo que ni está vivo ni está muerto, ha venido a recordarnos nuestra vulnerabilidad, ha llamado a nuestra puerta y nos ha dicho que somos solo una pieza más del entramado de un ecosistema global interconectado. Nos ha sacado de nuestra comodidad y de nuestro mundo lleno de certezas y nos ha lanzado contra la incertidumbre y joh sorpresa! la incertidumbre no sabemos gestionarla, nos genera malestar, ansiedad, inseguridad,... nunca hemos aprendido qué hacer con ella (Cardeñoso, Moreno, García-González, y Jiménez-Fontana, 2017).

Esta crisis cuyos orígenes apuntan al deterioro de los ecosistemas también nos pone frente a nuestra relación con la naturaleza, una relación fuertemente 
antropocentrista. Este nuevo virus, además, nos ha recordado que las fronteras no existen, que son un invento de las sociedades occidentales para separar a los grupos humanos, o más bien para separar a los pobres de los ricos. Aun así, aunque no existan estas fronteras, esta crisis no nos está afectando a todos los grupos humanos por igual, ni siquiera en los países con más recursos está incidiendo de la misma manera. La desigualdad se está haciendo aún más profunda en estos tiempos.

Sin restar importancia a todas estas cuestiones, si de algo nos está sirviendo esta cruel crisis es para parar. Sí, parar este ritmo frenético en el que nos vemos envueltas las personas, mirar en profundidad a las que tenemos al lado y a nosotras mismas. Cada cual en mayor o menor medida ha dedicado tiempo a las cosas realmente fundamentales a las que no damos importancia habitualmente. En el devenir de la pandemia han emergido muchas cuestiones que tenemos en el tintero, pero a las que nunca dedicamos el tiempo que necesitan, precisamente porque creemos que no disponemos de él. Así nace esta reflexión, del tiempo dedicado a entretejer ideas y pensamientos que estaban desde hacía rato en una bobina.

Por todo ello, mantenemos que las crisis son también una oportunidad para el cambio, son tiempos que despiertan la creatividad y que nos llevan una vez más a pensar y replantearnos cuál es nuestro papel, y en nuestro caso nuestro papel como educadores y educadoras en un mundo en constante cambio. Como decían Bonil, Junyent, y Pujol (2010), las crisis son una oportunidad para cambiar los modelos educativos.

En este nuevo escenario hacia el que nos dirigimos, eufemísticamente hablando, la mal llamada nueva normalidad, la vuelta a la escuela se está convirtiendo en un gran desafío. Muchas personas piensan que la escuela no está preparada, los padres y madres tienen miedo, desconfianza, los maestros y maestras a pesar de estar trabajando intensamente sin mayor reconocimiento social, se sienten en ocasiones desorientados e inseguros, ¿los que gobiernan?, ... Esto es harina de otro costal.

Estamos recibiendo algunas noticias e imágenes de cómo será la vuelta a las clases, que nos retrotraen a unas visiones de la escuela ya superadas, siendo tibias, son imágenes que dan escalofríos. Recuerdan más a una cárcel que a un lugar donde los niños y niñas deberían estar deseando llegar. Un lugar del que estén enamorados y donde se encuentran con sus maestras y maestros, con sus amigos y amigas, y con las oportunidades para acceder al saber y elaborar el conocimiento.

El principal reto de la vuelta a la escuela no puede ser intentar no ahondar en las cosas que sabemos que no funcionan o que hacemos porque así se han hecho siempre. Incluso se está diciendo abiertamente desde algunos sectores volveremos a la escuela de siempre. Por el contrario, la vuelta al aula debe ser un desafío creativo que por un lado nos impulse a integrar todas aquellas metodologías, recursos, ideas y pensamientos que dejamos usualmente de lado por falta de tiempo, miedo o desconfianza en nuestras capacidades y por otro lado, sea para que se recuperen muchas buenas costumbres que se han perdido en la escuela. Los educadores y educadoras debemos asumir el riesgo que todo ello supone y liderar el cambio.

Son muchas las intervenciones que pueden emprenderse en este sentido, pero en este escrito queremos poner en valor la idea de hacer escuela al aire libre, no solo porque la pandemia cuestiona la posibilidad de estar juntos en un espacio cerrado, sino 
porque la escuela al aire libre reporta numerosos beneficios a todos los niveles y no solo para niños y niñas. También para la comunidad educativa y a la postre para la sociedad.

\section{Aprender al aire libre}

Los niños y niñas de hoy viven inmersos en una crisis ecológica y de valores que demanda una nueva forma de relacionarnos con el entorno y la naturaleza, más bien llama a una re-conexión con esta. Es necesario poner a la naturaleza, entendida en sentido amplio, en el centro de los procesos educativos para no romper el vínculo genuino que todos los seres humanos tenemos con nuestro entorno. Un vínculo que debe mantenerse a través del contacto continuado con la naturaleza y que se va fortaleciendo a través de la experiencia y las emociones que esta nos transmite. Ello fomentará un comportamiento pro-ambiental a lo largo de nuestra vida (Hueso, 2019).

La educación al aire libre y en espacios naturales hace referencia a un concepto complejo de educación que toca una amplia gama de actividades educativas en muchos entornos diferentes (Rickinson et al., 2004). Nosotras la entendemos como una educación en, sobre y para el ambiente con una visión sostenible (Higgins, 1995), que pretende desarrollar competencias, conocimientos, procedimientos, habilidades y actitudes con respecto al mundo en el que vivimos (Ford, 1986). Implica pasar un tiempo significativo de la jornada escolar al aire libre, desarrollando diferentes actividades y tareas que permitan conocer y aprender, dentro del ambiente donde se producen diferentes procesos e interacciones de interés para los pequeños y pequeñas que además, faciliten una relación ética con el entorno. Se trata de ampliar la mirada hacia otros espacios ignorados donde es posible aprender y enseñar.

Los beneficios que esto aporta a los pequeños y pequeñas han sido y son aun ampliamente estudiados. El solo hecho de contemplar la naturaleza relaja nuestra fatiga mental. Además, proporciona beneficios en la salud (Hervás, 2005), mejoras en el aprendizaje (Wells, 2000) y en el desarrollo motor de los niños y las niñas (Fjortoft, 2001).

Como bien sabemos, el aprendizaje no se da en el vacío, sino que está fuertemente ligado a los contextos. Por tanto, cuanto más ricos y diversos sean estos contextos más enriquecedor, complejo y potencialmente significativo será el aprendizaje. Los espacios al aire libre ofrecen multitud de estímulos, además están sometidos a los cambios del tiempo, los niños y niñas son testigos de estos cambios, los observan y cuestionan (García-González y Schenetti, 2019). Estos espacios brindan a los niños y niñas el acceso a numerosos fenómenos para explorar, nuevos desafíos, diversidad de preguntas sin resolver y misterios por descubrir. Todos ellos difíciles de generar en espacios estáticos o poco dados al cambio, como puede ser un aula convencional. Asimismo, agudizan la tendencia de todo ser humano a aprender y enseñar pues fomentan el encuentro tanto con los iguales como con los maestros y maestras.

Hoy más que nunca, el aprendizaje no puede estar circunscrito a un solo lugar, sino que deben explorar diversos contextos que enriquezcan los procesos de enseñanzaaprendizaje en los que se ven envueltos los niños y niñas. Es necesario abrir las puertas del aula para construir conocimiento y pertenencia hacia el mundo en que vivimos. Establecer conexiones entre el aula y lo que ocurre fuera, conlleva integrar la 
realidad socio-ambiental en los procesos de aprendizaje. Ello fomenta en los niños y niñas la autonomía y la creatividad, desarrolla su espíritu de iniciativa, promueve la responsabilidad y su capacidad de compromiso con el entorno de manera que vaya calando en ellos una mirada sostenible sobre el mundo.

Educar en un contexto diferente al escolar de aula donde se combinan diversidad de escenarios, promueve la variedad de estrategias de aproximación al conocimiento. Además, la naturaleza es respetuosa con los tiempos de aprendizaje de los niños y niñas, con sus edades y desarrollo. Sus tiempos son más lentos a los de la escuela y se adaptan más fácilmente a los ritmos de los pequeños y pequeñas favoreciendo la atención a la diversidad existente en los todos los grupos humanos.

Salir al aire libre, cambiar los escenarios tradicionales de aprendizaje, supone un desafío para la comunidad educativa, pero cuando esta comprenda el potencial que tiene el aprendizaje en la naturaleza y los espacios abiertos, podrá aprovechar las oportunidades e integrarlas con sentido en los procesos de enseñanza-aprendizaje. Ello contribuirá asimismo a formar a niños y niñas con consciencia ambiental (Liefländer Fröhlich, Bogner y Schultz, 2013) y crecer desde la perspectiva de la sostenibilidad. Un imperativo ético si queremos que los niños y niñas tengan una vida plena y en sintonía con el mundo que los rodea.

En España existen ya numerosas iniciativas de aprendizaje al aire libre. Una de las experiencias pioneras en este sentido fue el Grupo de Juego en la Naturaleza Saltamontes, al que le han seguido otras escuelas en espacios peninsulares e insulares Muchas de ellas organizadas en la Asociación Nacional de Educación en la Naturaleza (EdNA) que defiende la importancia y necesidad de incluir el contacto con la naturaleza en los procesos formativos desde las etapas tempranas. En la situación actual en la que una vuelta a la escuela segura pasa por estar más tiempo al aire libre, estas iniciativas tienen mucho que aportar. Escuchemos atentamente, empapémonos de su experiencia y sus saberes y creemos sinergias con la escuela convencional.

\section{La escuela al aire libre ¿una nueva escuela?}

Por muy innovador y original que pueda parecer el hecho de hacer escuela al aire libre, lo cierto es que la naturaleza ha estado presente en el ámbito educativo desde principios del siglo pasado, aunque quizá no con toda la fuerza que mereciera. Por eso hemos llamado este escrito re-naturalizar la escuela, porque la escuela ya estuvo naturalizada como esbozamos líneas abajo. Y por ello, sugeríamos al inicio de esta reflexión, que es necesario retomar viejas y buenas costumbres.

En España la Institución libre de Enseñanza apostaba por un contacto permanente y directo con la naturaleza. Dentro de los movimientos de la Escuela Nueva se incluía como principio innovador básico el contacto continuado con la naturaleza y el conocimiento de las leyes que la rigen (Marín, 1976; Pozo, 2003). En 1914 nace la primera Escuela Bosque de Rosa Sensat. Sobre 1968 empiezan a invadir la escuela las nuevas pedagogías propuestas por Freinet, se comienzan a trasponer las ideas de Piaget, y se produce el movimiento de renovación pedagógica que apuesta por el contacto con el entorno. Un ejemplo significativo en este campo es el proyecto $L a$ ciudad de los niños impulsado por Tonucci y que se ha puesto en marcha en numerosas ciudades y barrios de todo el mundo (Tonucci, 2005). Actualmente tenemos una potente red de eco-escuelas en el territorio español digno de ser 
mencionado. Asimismo, el movimiento de los huertos escolares es cada vez más potente (Rodríguez-Marín, Fernández-Arroyo y García, 2015). No obstante, pensamos que la naturaleza y sus interrelaciones deben ser el centro de los procesos educativos y no solo un complemento añadido.

Y ¿cómo lo hacemos? ¿por dónde empezamos? Claramente no existe una respuesta única a estas preguntas. Se trata de una cuestión sobre la que llevamos un tiempo reflexionando. Sin llegar a una conclusión clara, sí que estamos de acuerdo en que debemos empezar dando pequeños pasos, pasos abordables: ¡salgamos al patio! ¡ocupémoslo!

Si bien es cierto que muchos de los diseños de nuestros patios son cuestionables, algunos hasta hostiles, en todos ellos se pueden encontrar rincones aprovechables. Un simple árbol puede ofrecer multitud de oportunidades para el aprendizaje. Se puede trepar, se puede abrazar, se puede rodear, ... Pero también se puede medir su tronco o su altura, calcular su edad, se le pueden cortar sus hojas, se pueden comparar éstas para clasificarlas como formas o hasta como figuras geométricas, se pueden explorar las diferentes especies que viven en él o incluso se puede leer un buen libro a su sombra o llegar a escribir un relato sobre el mismo.

Además, en los patios suele haber arena con la que se pueden indagar infinidad de cuestiones e incluso cocinar si tenemos agua a mano, podemos encontrar distintas hierbecillas que se atreven a nacer entre las rendijas, numerosos insectos, podemos mirar al cielo y sobre todo, podemos sentir el viento, el calor, el frío, ... En fin, nuestro clima y sus estaciones. Un clima con el que vivimos en guerra, el buen tiempo es solo aquel soleado. Horroriza ver como los niños y niñas salen corriendo despavoridos a guarecerse cuando llueve en lugar de seguir jugando, pero ahora con el agua, ¿qué les estamos enseñando? En lugar de agua parece que cayeran meteoritos.

Pasemos más tiempo fuera de esas cuatro paredes clásicas y no solo 30 minutos al día, que son los únicos en que los niños y niñas pueden hacer suyo el patio. Si no salimos no podremos ocuparlo, no podremos hacerlo nuestro. Hagamos del patio un espacio amable, de convivencia, de juego y de aprendizaje. Pasar tiempo en el patio nos llevará a reflexionar sobre cómo modificarlo, pues irán surgiendo nuevas necesidades educativas. Este proceso de cambio puede derivar en un diálogo enriquecedor en el que participe toda la comunidad educativa. Si todo esto se puede hacer solo en el patio ¿qué nos deparará ir más allá de los muros de la escuela?

Fuera están los parques, los jardines, los solares abandonados, los bosques, las playas, los equipamientos ambientales, ... Espacios que también son escuela y donde las posibilidades de aprendizaje se multiplican. En ellos además del evidente cambio de escenario entra en juego el contacto con nuevas personas con lo que ello conlleva de emocionante y novedoso.

Estar fuera conlleva más trabajo, aunque más bien el esfuerzo reside en romper con lo tradicional, es un paso costoso inicialmente pero que pronto se convierte en una situación de no retorno, la mayoría de maestros y maestras que dan el paso, no quieren volver al aula (Schenetti y Guerra 2018). Educar al aire libre implica cambios en las relaciones entre maestros y maestras y niñas y niños que vienen propiciados por el propio ambiente, diferente al aula, donde se abren infinidad de oportunidades de aprendizaje y de relaciones. Además, los espacios al aire libre son inspiradores 
para los maestros y maestras, vehiculan cambios metodológicos innovadores. Ello conduce a descartar, las actividades estructuradas, cerradas y de corte tradicional provistas por los libros de texto que resultan muy limitadas para los complejos procesos de enseñanza-aprendizaje que se desarrollan en estos escenarios. Además, implica repensar los espacios de la escuela para orientarlos hacia estas nuevas perspectivas.

En este camino de cambio creemos que es necesario crear simbiosis, escuchemos a aquellas que tienen conocimiento y experiencia, como los educadores y educadoras ambientales, acompañantes imprescindibles en este camino, pongamos en valor el papel de muchas maestras y maestros de las escuelas públicas que están trabajando en esta línea, divulguemos conocimiento y formemos a los nuevos educadores con una nueva mirada que integre una diversidad de espacios de aprendizaje.

A modo de cierre, las reflexiones que hemos puesto de manifiesto a lo largo del escrito no son nuevas, ni las hemos inventado nosotras. Son cuestiones por las que, desde muchos ámbitos, profesionales de la educación, a todos los niveles, y padres y madres implicados en la educación de sus hijos e hijas, han luchado y siguen luchando. Los motivos para el cambio no son solo los derivados de la crisis sanitaria en la que estamos inmersas, pero si esta nos ha servido para llamar la atención de muchos sectores dormidos, no dejemos pasar la ocasión, agarrémosla con fuerza para emprender el camino de transformación de la escuela. Un camino que, desde nuestra óptica, debe liderar la escuela pública.

\section{Referencias}

Bonil, J., Junyent, M., y Pujol, R. M. (2010). Educación para la sostenibilidad desde la perspectiva de la complejidad. Revista Eureka sobre Enseñanza y Divulgación de Las Ciencias, 7(Número Extrsordinario), 198-215.

Cardeñoso, J. M., Moreno, A., García-González, E., y Jiménez-Fontana, R. (2017). El sesgo de equiprobabilidad como dificultad para comprender la incertidumbre en futuros docentes argentinos. AIEM - Avances de Investigación en Educación Matemática, (11), 145 - 166.

Fjortoft, I. (2001). The Natural Environment as a Playground for Children: The Impact of Outdoor Play Activities in Pre-Primary School Children. Early Childhood Education Journal, 29(2), 111-117. https://doi.org/10.1023/A:1012576913074.

Ford, P. (1986). Outdoor education: Definition and philosophy (Report № RC 015 661). Las Cruces, NM: ERIC Clearinghouse on Rural Education and Small Schools. (ERIC Document Reproduction Service No. ED 267 941) http://files.eric.ed.gov/fulltext/ED267941.pdf

García-González, E., y Schenetti, M. (2019). Las escuelas al aire libre como contexto para el aprendizaje de las ciencias en infantil. El caso de la Scuola en el Bosco Villa Ghigi. Revista Eureka sobre Enseñanza y Divulgación de las Ciencias., 16(2), $1-15$. https://doi.org/10.25267/Rev_Eureka_ensen_divulg_cienc.2019.v16.i2.2204

Hervás, L. (2015). Aprender en la naturaleza: la experiencia de las escuelas bosque en España.

Revista inspira.

Recuperado 
dehttp://www.mapama.gob.es/es/ceneam/articulos-de-opinion/2015-07-08hervas_tcm7-387348.pdf.

Higgins, P. (1995). Outdoor education provision at Moray House Institute of Education. Scottish Journal of Physical Education, (23), 4-12.

Hueso, K. (2019). Jugar al aire libre. Barcelona: Plataforma Editorial.

Liefländer, A. K., Fröhlich, G., Bogner, F. X., y Schultz, P. W. (2013). Promoting connectedness with nature through environmental education. Environmental Education Research, 19(3), 370-384. https://doi.org/10.1080/13504622.2012.697545.

Marín Ibáñez, R. (1976). Los ideales de la escuela nueva. Revista de Educación, (242), 23-42.

Pozo Andrés, M. (2003). La Escuela Nueva en España: crónica y semblanza de un mito. Historia de La Educación: Revista Interuniversitaria, (22), 317-346.

Rickinson, M., Dillon, J., Teamey, K., Morris, M., Choi, M. Y., Sanders, D., y Benefield, P. (2004). A review of research on outdoor learning. National foundation for educational research and King's college London. London: National Foundation for Educational Research and King's College London Research.

Rodríguez-Marín, F., Fernández-Arroyo, J. y García, J. E. (2015). El huerto escolar ecológico como herramienta para la educación en y para el decrecimiento Investigación en la escuela, (86), 35-48.

Schenetti M., y Guerra E. (2018) 'Emotion Map Making. Discovering Teachers' Relationships with Nature', Asia-Pacific Journal of Research in Early Childhood Education, 12(2), 31-56.

Tonucci, F. (2005). La ciudad de los niños. Bracelona: Editorial Graò.

Wells, N. M. (2000). Effects of Greenness on Children's Cognitive Functioning. $\begin{array}{llll}\text { Environment } \text { and } & \text { 32(6), }\end{array}$ https://doi.org/10.1177/00139160021972793. 